\title{
Powder X-Ray Diffraction Laboratory, Reston, Virginia
}

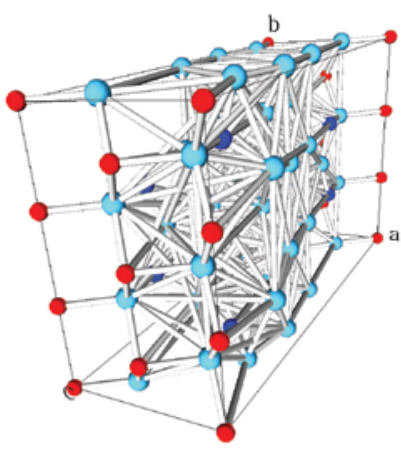

\section{Overview}

The laboratory operates a 45-position PANalytical $\mathrm{X}^{\prime}$ Pert Pro ${ }^{1}$ diffractometer, using either copper or cobalt $\mathrm{K} \alpha$ radiation. X-ray diffraction peaks are produced by constructive interference of a beam of $\mathrm{X}$-rays scattered at specific angles from each set of crystal lattice planes in a sample. A characteristic set of peaks and peak intensities provide a fingerprint of a given phase. Software is used for spectral pattern processing, phase identification, crystallographic analysis, cluster analysis, semiquantitative mineralogical analyses by Rietveld refinement, and structure determination.

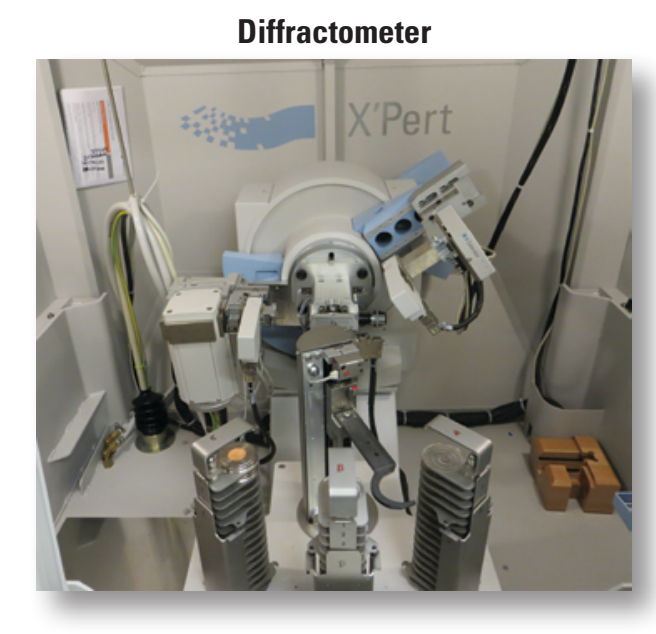

Laboratory features include the following:

High speed non-destructive XRD analysis;

Qualitative and quantitative mineralogical analysis;

User-friendly software to collect and interpret diffraction data;

Phase identification on very small sample quantities and on very fine-grained materials;

Mineralogical cluster analysis for processing large groups of samples quickly;

Minimum phase detection limits as low as 1 weight percent; Physical and chemical mineral separation techniques;

Quality control procedures tailored to each application; and X-ray fluorescence capabilities to aid in chemical and mineral identification.

${ }^{1}$ Use of product names does not constitute endorsement by the U.S. Government.

\section{Analysis by XRD is applied to a variety of studies:}

- Coal and petroleum assessments

- Ore genesis

- Mineral-resource assessments

- Remote sensing

- Soil geochemical landscapes

- Lake and stream sediments

- Rare earth element resources

- Paleoclimate (such as paleosols and evaporites)

- Environmental behavior of mineral deposits and energy resources

- Industrial minerals

- High pressure indicator minerals from impact craters

- Anthropogenic and geologic source materials

\section{Prospective Gas Shale from Mississippi}

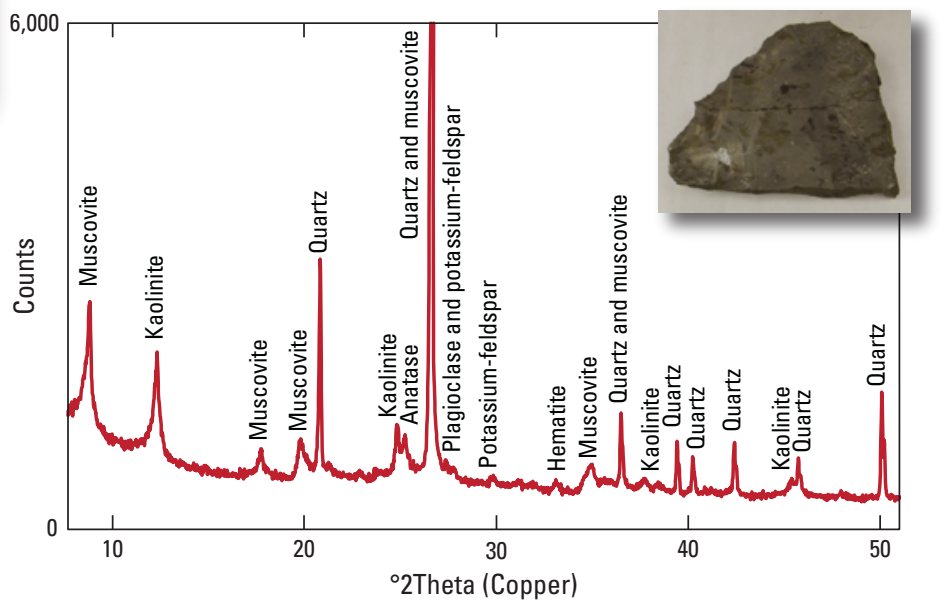

Anatase 1 wt. \%

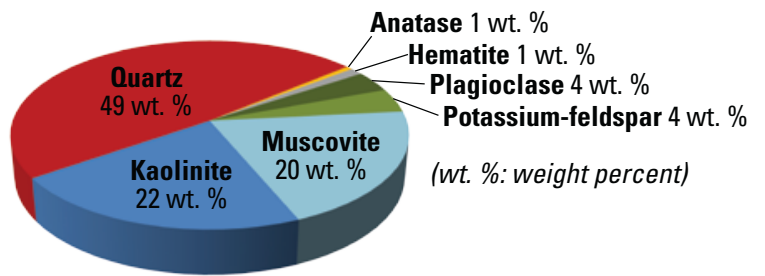




\section{Capabilities and Applications}

\section{Ore Deposits}

Mineralogical characterization of ore and associated rocks, including fine-grained hydrothermal alteration minerals, is used to understand the conditions in which ore deposits are formed and are altered to help determine whether a deposit is economically viable. Ore mineralogy is a critical component of mineral-resource assessments.

\section{Unconventional Energy Resources}

Detailed mineralogical data for unconventional energy sources such as shales can aid in distinguishing stratigraphic zones, provide insight into engineering properties, and help identify intervals for hydraulic fracturing. Current (2014) research activities include examining shales in the United States that are prospective gas and oil reservoirs.

\section{Organics and Coal}

$\mathrm{X}$-ray diffraction analysis of coal, coke, and oil sand, shale, and other petroleum source rocks yields important information on their formation and utilization potentials. A unique capability of the laboratory includes low temperature oxidation ashing (LTA) for gravimetric determination of loss on ignition, which is a proxy for total organic content. The LTA procedure concentrates the mineral phases, allowing for identification of crystalline phases originally present in very low concentrations.

\section{Soils and Sediments}

Accurate and fast quantitative mineral analysis by Rietveld refinement was the key to completing over 5,000 soil sample analyses for the Geochemical Landscapes Project to mineralogically characterize U.S. soils. An extensive quality assurance program was established to determine confidence in the data generated in the lab.

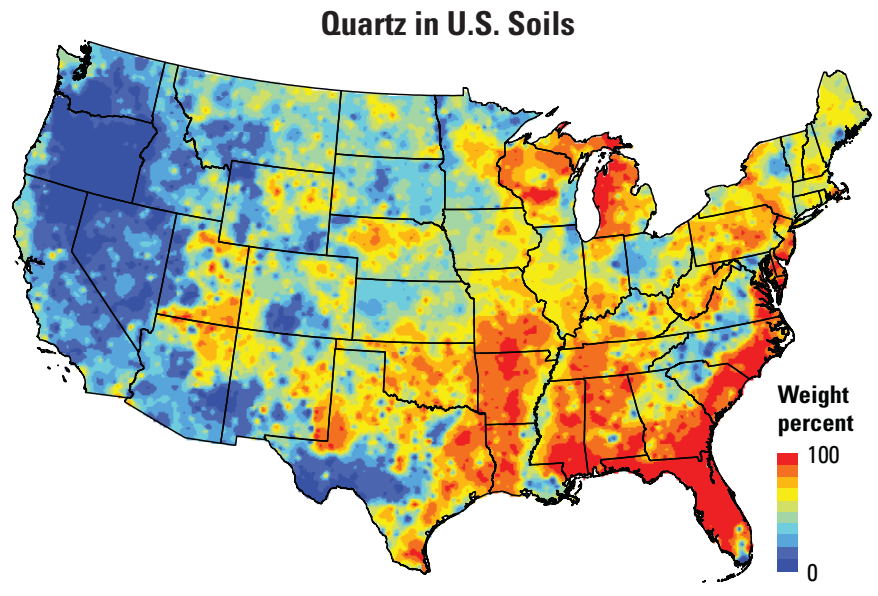

\section{Clays Minerals}

Clay mineral analysis is essential to (1) understanding diagenetic changes observed in petroleum reservoirs and physical and chemical behavior of soils, (2) determining mineral purity in industrial minerals, and (3) identifying clay mineral polytypes in rocks from ore deposits. The primary method of identifying and characterizing clays is by XRD analysis, which typically requires preparation and analysis of multiple samples splits. The laboratory is equipped to disaggregate clays, separate grain sizes, treat clays with exchangeable cations and organic solvents, heat and dry samples, and prepare oriented- and random-powder sample mounts.

\section{Rare Earth Element Minerals}

$\mathrm{X}$-ray diffraction phase identification and quantification are useful for determining the distribution of rare earth elements deposits, and deciphering the processes that lead to their concentration, particularly in residual deposits. Targeted minerals are separated and concentrated using heavy liquids, and analyzed by XRD. The mineral separates subsequently are used in radiogenic isotope and zircon/apatite age determination studies.

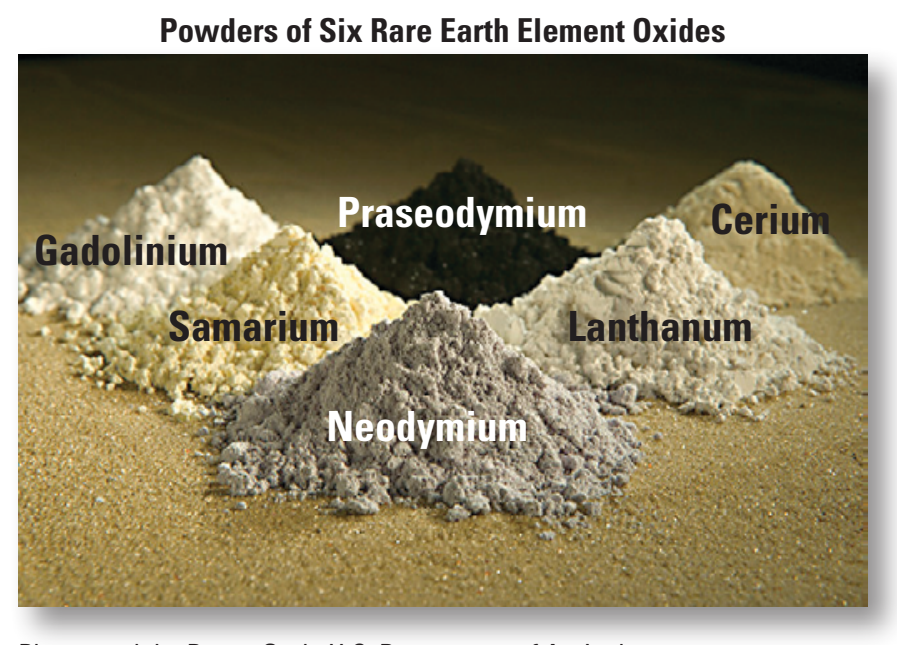

Photograph by Peggy Greb, U.S. Department of Agriculture.

\section{Amorphous Phases}

X-ray diffraction analysis is used to identify the presence, estimate the proportion, and acquire compositional information of amorphous or poorly crystalline phases, which are ubiquitous in many natural and synthetic materials. Amorphous characterization has been used to evaluate mine waste as an environmental contaminant and as a potential resource for reuse or additional metal recovery.

For additional information, contact:

John C. Jackson Email: jjackson@usgs.gov Email: fdulong@usgs.gov

Nadine M. Piatak

Email: npiatak@usgs.gov 